\title{
Identification of Optimum Composition and Mechanical Properties of Al-Ni Metal Matrix Composite
}

\author{
Manoj Kumar Pal' ${ }^{1}$, Simranjeet Singh Sandhu', Rohan Kalia', Arka Ghosh ${ }^{2}$ \\ ${ }^{1}$ Department of Mechanical Engineering, SRM University (NCR Campus), Ghaziabad, India \\ ${ }^{2}$ ISBR Business School, Bangalore, India \\ Email: manojsantosh2002@gmail.com, singh_simranjeet@ymail.com, rohan.capricorn@gmail.com, \\ arka.ghosh29@gmail.com
}

Received 15 June 2015; accepted 5 July 2015; published 8 July 2015

Copyright $@ 2015$ by authors and Scientific Research Publishing Inc.

This work is licensed under the Creative Commons Attribution-NonCommercial International License (CC BY-NC).

http://creativecommons.org/licenses/by-nc/4.0/

(c) $\underset{\mathrm{EY}}{\mathrm{E}(9)}$ Open Access

\begin{abstract}
Composites are materials that are made up of two or more chemically dissimilar phases. In this project aluminum was chosen as matrix material because it was inexpensive, light-weight, strong, tough and corrosion resistant. For the main load bearing phase it was hard, corrosion resistant at room temperature and thermally stable. The stir casting method was used because it was cost-effective and easy, and the particulate reinforcement (nickel) was uniformly distributed throughout the matrix phase. Sand moulding was used to cast the specimens. Specimens with 10, 20, 30 and 40 percentage Nickel were tested and the optimal specimen contained $20 \%$ Nickel. The Brinell hardness of $\mathrm{Al}+20 \% \mathrm{Ni}$ increased by $14.80 \%$, Rockwell hardness increased by $2.43 \%$, ultimate tensile strength increased by $1.003 \%$ and thermal conductivity of $\mathrm{Al}+20 \%$ Ni decreased by $24.98 \%$ with respect to Aluminum.
\end{abstract}

\section{Keywords}

Metal Matrix Composite, Aluminum (Al), Nickel (Ni), Fabrication, Testing, Composite

\section{Introduction}

For the past several years, research has focused on fabrication of light and strong materials. Composites are used to increase mechanical properties like stiffness and toughness. Composites made up of matrix (continuous) phases, and a dispersed phase that surrounds the matrix phase (the two phases) should be chemically dissimilar. 
The properties of composites generally depend on the geometry and amounts of the constituent phases. Composite materials include:

1) Ceramic Matrix composites;

2) Polymer Matrix Composites;

3) Metal Matrix Composites (MMCs).

MMCs have higher strength, ductility and temperature stability than ceramic or polymer matrix composites [1]-[3]. Such properties of MMCs provide a platform for its application in the automotive and aerospace industries [4]-[7]. Aluminium has a Young's Modulus of $70 \mathrm{GPa}$ and yield strength of $35 \mathrm{MPa}$. Nickel has a Young's Modulus of $200 \mathrm{GPa}$. The combination of reinforcing phase and metal matrix can be realized with the help of techniques such as liquid state processing, powder metallurgy, and solid state processing [8]. Reinforcing materials are of types such as 1) Whiskers, 2) Particles, 3) Laminated, and 4) Discontinuous or Continuous fibres [7] [9]. Nowadays particulate-reinforced MMCs are getting a lot of attention due to its easier fabrication methods and good availability of variety of reinforcements. The properties of MMCs are dependent on many factors such as type of processing method, volume fraction, type of matrix, and geometry of reinforcement.

There are several techniques for fabricating MMC like Stir casting, Powder metallurgy, Gas infiltration, Spray forming, Chemical vapor deposition, Electroplating, etc. Out of all these techniques, Stir casting is the most common as it is simple to use as well as it is cost effective in nature.

\subsection{Matrix Materials}

Aluminum, Titanium, Magnesium and their alloys are mostly used as matrix materials. The cost effectiveness, light weight, good strength, toughness and corrosion resistance of Aluminum have made us choose it as matrix material [3] [10] [11]. But poor mechanical properties of Aluminum limit its wider use [3].

\subsection{Reinforcement Material}

It is also called dispersed phase and used in composite to strengthen and stiffen. Properties such as physical, mechanical properties and cost effectiveness are important for selection of reinforcement [1] [12]. In recent times it has been observed that there has been more attention towards particulate-reinforced MMC. The advantages of particulate-reinforced MMCs are reduction of weight, machinable, workable, enhanced physical and chemical properties [13]. In particulate-reinforced MMCs, the metal matrix as well as the reinforcement particles shares the load. In our research, use of particles of Nickel was made as reinforcement due to higher hardness and corrosion resistance of Nickel. In sharing of load between the matrix and particles, the load is transferred through the interface between the matrix and particles. The biggest problem in good load transfer is the proper bonding between the matrix and the reinforcement. It is to be kept in mind that not all the matrix and reinforcement combinations are compatible and may not be fabricated commercially. Moreover, in some cases the bonding between reinforcement and matrix is poor so that some adhesion promoters are used to strengthen the bonding while in some composites excess of interfacial reactivity may case a brittle layer around the reinforcement. Various types of reinforcement are used in aluminum matrix such as $\mathrm{SiC}, \mathrm{TiC}, \mathrm{Ni}, \mathrm{TiB}_{2}, \mathrm{Al}_{2} \mathrm{O}_{3}$, etc.

\section{Fabrication}

There are a lot of methods for fabricating metal matrix composites. They are divided in various categories such as:

- Liquid phase process;

- Solid-solid process;

- Deposition process;

- In-situ process;

- Solid-liquid process.

The relation between the properties and cost of the constituent materials of the MMC is determined by the fabrication process used. There are two techniques for incorporating the reinforcement in the matrix:

1) Ex-situ process - in which incorporation of reinforcement particle is done with the help of stirring, blending or injection;

2) In-situ process - here the reinforcement phase is prepared by some reaction process between constituents 
of MMC to form Carbides, Nitrides, Silicates, and Borides [14].

The melt stir casting is a very good option for fabricating MMCs due to its inherent advantages such as the flexibility, simplicity, applicability to a lot of volume, wide processing conditions and selection of materials, large sized parts can also be fabricated easily. Moreover, stir casting is one of the economical ways of distributing the reinforcement particles uniformly in the MMC system [15]. Stir casting make sure that the reinforcement material is not damaged [16]. It is a popular method as its cost of processing is just one third or half of the cost of the other fabrication methods.

The thing which is the most important during fabrication of MMC by stir casting method is that the reinforcement in the matrix should be uniform otherwise the properties will not be uniform in the specimen. Some of the common problem in stir casting methods is sedimentation and agglomeration of reinforcing particles, solidification of melt; impurities can get mixed with the melt, sometimes air gets trapped in the melt deteriorating the quality of MMC fabricated. The stir casting normally consist of the melting the matrix material in a crucible followed by stirring of that molten material to from a vortex and then reinforcement particles are incorporated in the vortex.

In stir casting process the Aluminum was melted in the furnace at a temperature of $700^{\circ} \mathrm{C}$ in a graphite crucible and then preheated Nickel particles were poured in the same crucible containing the molten Aluminum and temperature was increased till $1000^{\circ} \mathrm{C}$. The amount of Nickel was put one by one in percentages of $10 \%, 20 \%$, $30 \%$ and $40 \%$. After that the mixture of both the metals was stirred at $200-1000 \mathrm{rpm}$ for some time. When complete mixture of Aluminum and Nickel was mixed properly then specimen with 10\%, 20\%, 30\% and 40\% Nickel were sand casted (ref. Figure 1) and four different specimens of composites were prepared (see Figure 2).

\section{Experimental Setup}

\subsection{Tensile Testing}

A tensile test measures the resistance of a material to a static or slowly applied force. A machined specimen is placed in the testing machine and load is applied. All the specimens that are $90 \% \mathrm{Al}+10 \% \mathrm{Ni}, 80 \% \mathrm{Al}+20 \%$ $\mathrm{Ni}, 70 \% \mathrm{Al}+30 \% \mathrm{Ni} \& 60 \% \mathrm{Al}+40 \% \mathrm{Ni}$ are one by one tested on the Universal Testing Machine. A Strain Gage

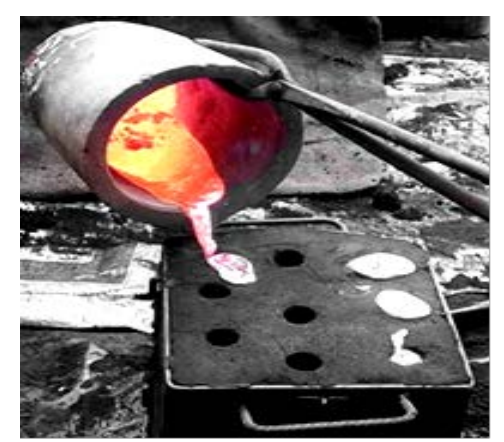

Figure 1. Sand casting being done to prepare the specimens.

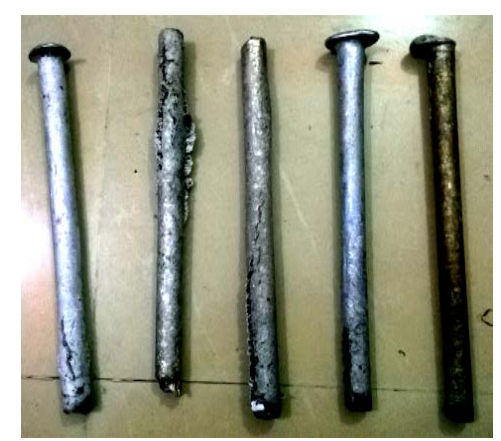

Figure 2. Al-Ni specimens having compositions of $0 \%, 10 \%$, $20 \%, 30 \%$ and $40 \%$ nickel from left to right respectively. 
or Extensometer is used to measure elongation. The stress obtained at the highest applied force is the Tensile Strength. The yield Strength is the stress at which a prescribed amount of plastic deformation (commonly $0.2 \%$ ) is produced. Elongation describes the extent to which the specimen stretched before fracture. Information concerning the strength, stiffness and ductility of a material can be obtained from a tensile test. The readings got are given in Table 1 and a corresponding graph is also shown in Figure 3.

\subsection{Rockwell Hardness Testing}

The Rockwell Hardness test makes use of indentation to measure the hardness of the different specimens. The machine generally has different types of scales to get the readings but here $\mathrm{C}$ scale was used to check the readings. The specimen is first loaded with the help of minor load then after that major load is applied with the minor load still applied. The indentation on the specimen is done by the indenter then reading is noted on the $\mathrm{C}$ scale and a dimensionless number of hardness is got in the form of HRC number. If the penetration of indenter is more the hardness will be less and vice-versa. Readings of the test are given below (see Table 2) and a graph for the hardness number of the four specimens is plotted (see Figure 4).

\subsection{Brinell Hardness Testing}

Brinell Hardness Test is more or less same like Rockwell Hardness test but the difference is that we use a formula to get the hardness in units such as $\mathrm{kg} / \mathrm{mm}^{2}$ etc. Steel ball indenter was used here and a load of $3000 \mathrm{kgf}$

Table 1. Ultimate tensile strength of the specimens obtained during tensile testing of specimens in universal testing machine.

\begin{tabular}{cc}
\hline Percentage of Nickel & Ultimate Tensile Strength $\left(\mathrm{N} / \mathrm{mm}^{2}\right)$ \\
\hline 10 & 1295 \\
20 & 1308 \\
30 & 962 \\
40 & 918 \\
\hline
\end{tabular}

Table 2. Rockwell hardness number of the specimens obtained during rockwell hardness testing of specimens in $\mathrm{C}$ scale.

\begin{tabular}{ccc}
\hline Percentage of Nickel & Rockwell Hardness Number (HRC) \\
\hline 10 & 41 \\
20 & 42 \\
40 & 29 \\
\hline
\end{tabular}

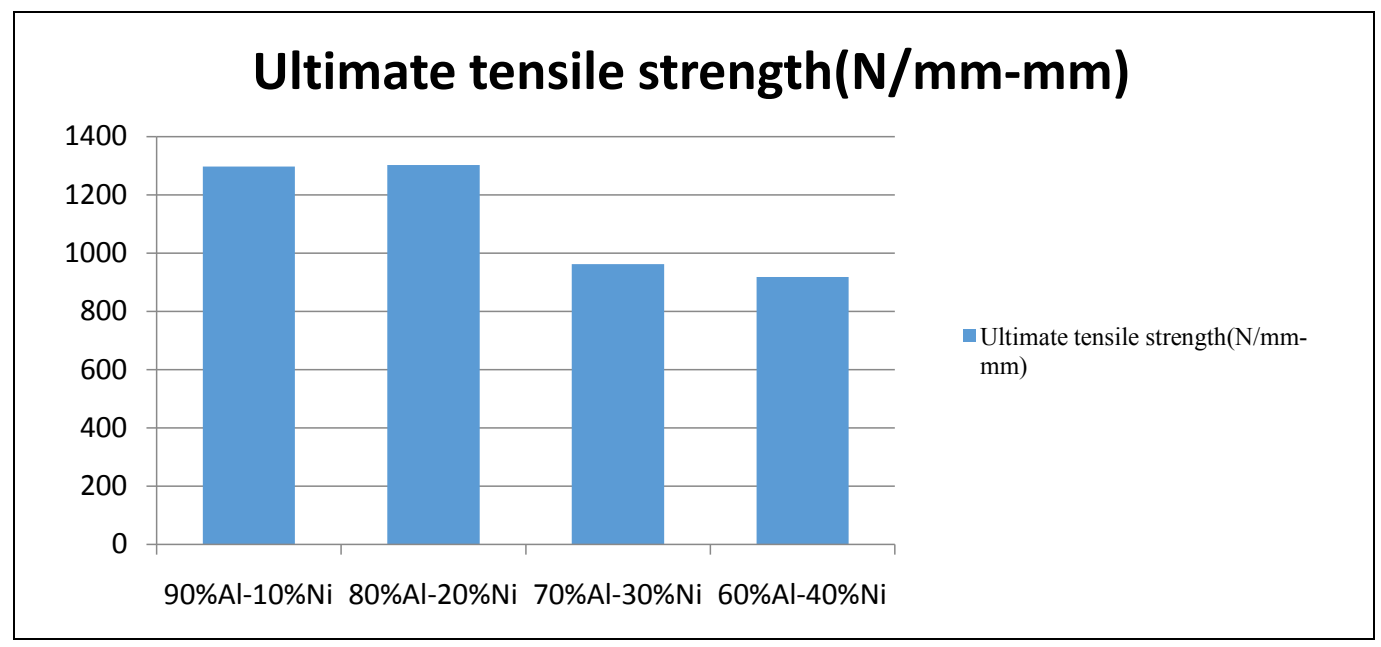

Figure 3. Graph showing the ultimate tensile strength variation across the specimens. 
was used on the four composites specimens. The diameter of the ball was $10 \mathrm{~mm}$. Then readings were found out for all the specimens and noted in a table (see Table 3) and a graph (see Figure 5) was plotted for the same.

\subsection{Thermal Conductivity Test}

This property tells us about how much a material conducts heat easily. If this property is high then material conducts heat more and if it is lower than material conducts heat less. The material with known conductivity is placed on both sides of fabricated specimens.

The heat transfer takes place with the help of heater and process of heating was convection. When specimens have a steady state then readings are noted down which are as follows (see Table 4) and a graph is plotted too (see Figure 6).

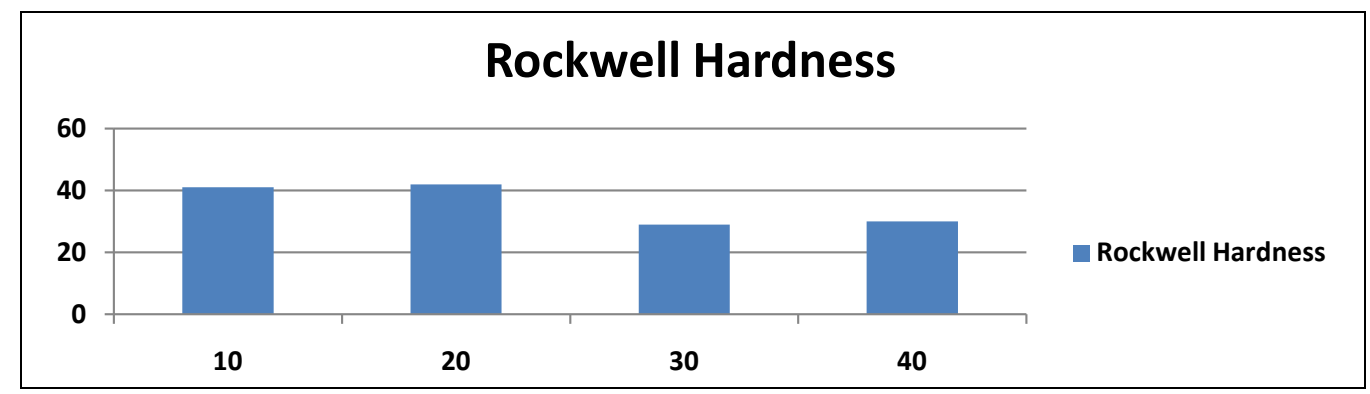

Figure 4. Graph showing the Rockwell hardness variation across the specimens.

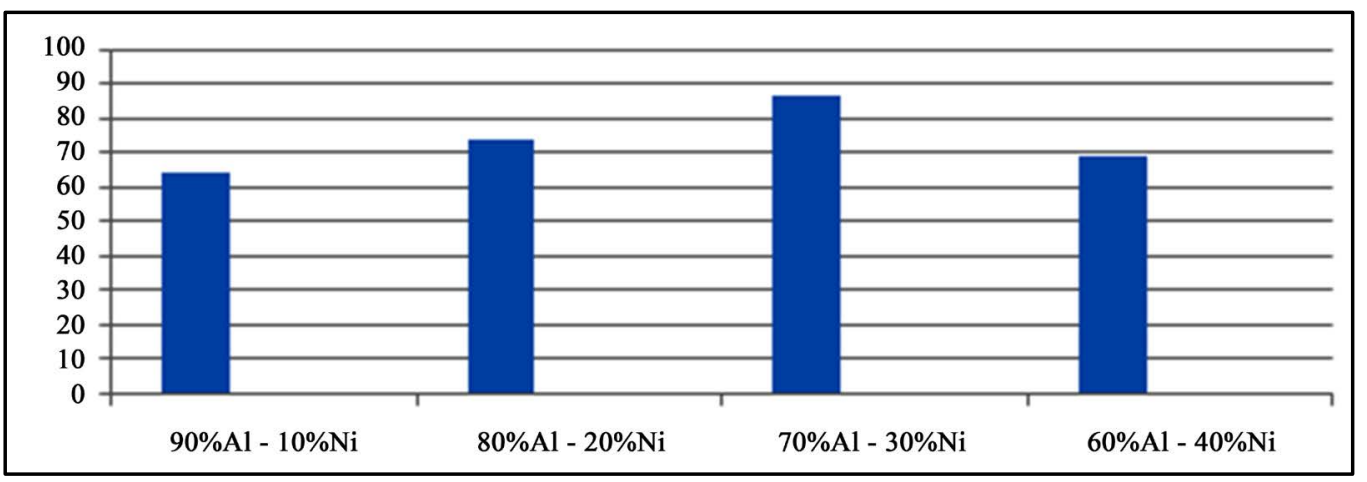

Figure 5. Graph showing the Brinell hardness variation across the specimens.

Table 3. Brinell hardness of the specimens obtained during brinell hardness testing of specimens under a load of $3000 \mathrm{kgf}$ and steel ball indenter having $10 \mathrm{~mm}$ diameter.

\begin{tabular}{cc}
\hline Percentage of Nickel & Brinell Hardness $\left(\mathrm{kg} / \mathrm{mm}^{2}\right)$ \\
\hline 10 & 64.56 \\
20 & 74.12 \\
30 & 87.05 \\
40 & 69.15 \\
\hline
\end{tabular}

Table 4. Thermal conductivity of the specimens obtained during thermal conductivity test of specimens by placing material of known conductivity on both sides of the specimen.

\begin{tabular}{cc}
\hline Percentage of $\mathrm{Ni}$ & Thermal Conductivity(W/mK) \\
\hline 10 & 213.3 \\
20 & 160 \\
30 & 175.9 \\
40 & 140.2 \\
\hline
\end{tabular}




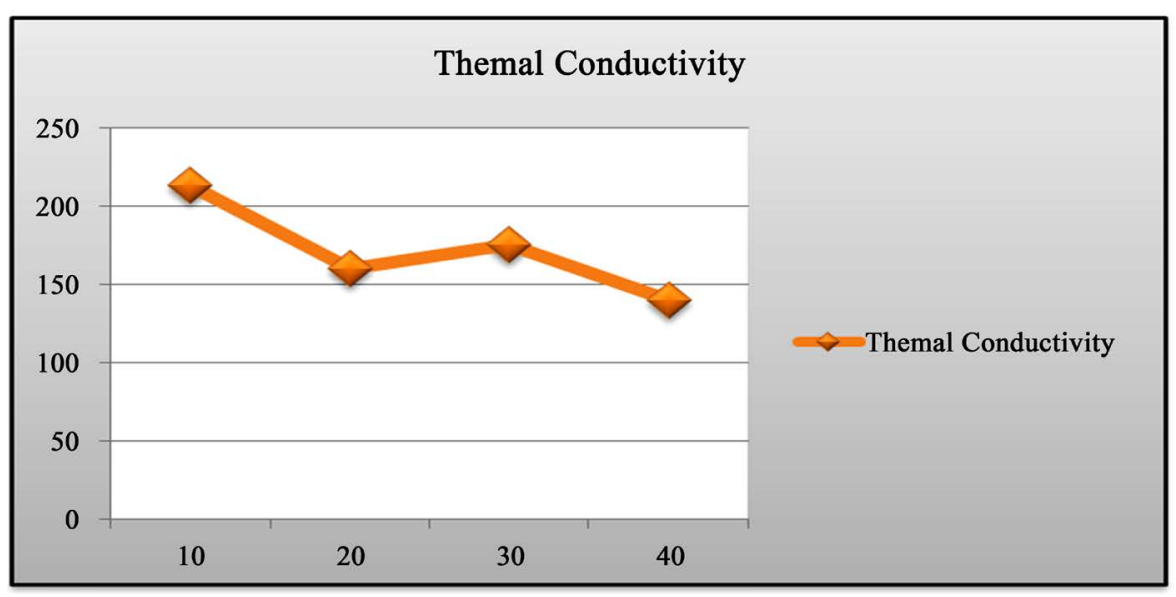

Figure 6. Graph showing the thermal conductivity variation across the specimens.

\subsection{Micro-Structural Analysis}

The microstructures of the $90 \% \mathrm{Al}-10 \% \mathrm{Ni}$ (see Figure 7), $80 \% \mathrm{Al}-20 \% \mathrm{Ni}$ (see Figure 8 ), $70 \% \mathrm{Al}-30 \% \mathrm{Ni}$ (see Figure 9) and $60 \% \mathrm{Al}-40 \% \mathrm{Ni}$ (see Figure 10) are found out. In the process to find the microstructure of the above specimens some processes were followed namely:

- Belt Polishing;

- Sand Paper;

- Double Disc Polishing;

- Etching.

\section{Result and Discussion}

After considering all the readings of the four specimens it can be said with confidence that the specimen $80 \% \mathrm{Al}-$ $20 \% \mathrm{Ni}$ shows better properties. The tensile strength of this specimen was found out to be $1308 \mathrm{~N} / \mathrm{mm}^{2}$, while the Rockwell hardness was found out to be 42HRC. Moreover, Brinell hardness was $74.12 \mathrm{~kg} / \mathrm{mm}^{2}$ and Thermal conductivity was $160 \mathrm{~W} / \mathrm{mk}$. All these readings clearly suggest that $80 \% \mathrm{Al}-20 \% \mathrm{Ni}$ is a valuable piece of MMC which if researched thoroughly provide us with a lot of valuable information for its usage in the industry.

Furthermore, after careful examination and testing of all the fabricated $\mathrm{MMC}(\mathrm{Al}+20 \% \mathrm{Ni})$ we can say that due to the different percentage of Nickel in different specimens there are variations in their properties. This behavior can be attributed to the interaction between Aluminum and Nickel at different percentages. These variations in properties in this metal matrix composite are also due to the following parameters:

1) Type of Reinforcement;

2) Type of Manufacturing Process;

3) Defects;

4) Percentage of Nickel;

5) Size of the particles;

6) Impurities.

Properties for different specimen were noted down and were plotted on a graph. There was an inconsistency in the nature of the graph plotted. So, to give an idea of the testing values in a nutshell the graph is provided (see Figure 11).

\section{Conclusions}

After testing of the specimens, $\mathrm{Al}+10 \% \mathrm{Ni}, \mathrm{Al}+20 \%, \mathrm{Al}+30 \% \mathrm{Ni} \& \mathrm{Al}+40 \% \mathrm{Ni}$ with different percentages of the Nickel results were noted down and were thoroughly investigated. The Brinell hardness, high tensile strength and lower thermal conductivity were better in the specimen containing $20 \%$ nickel (see Table 5). In the micro-structure of Al- $20 \% \mathrm{Ni}$, we can see the presence of nickel (golden color). The nickel is present as strips of golden color on the silvery white aluminum. 


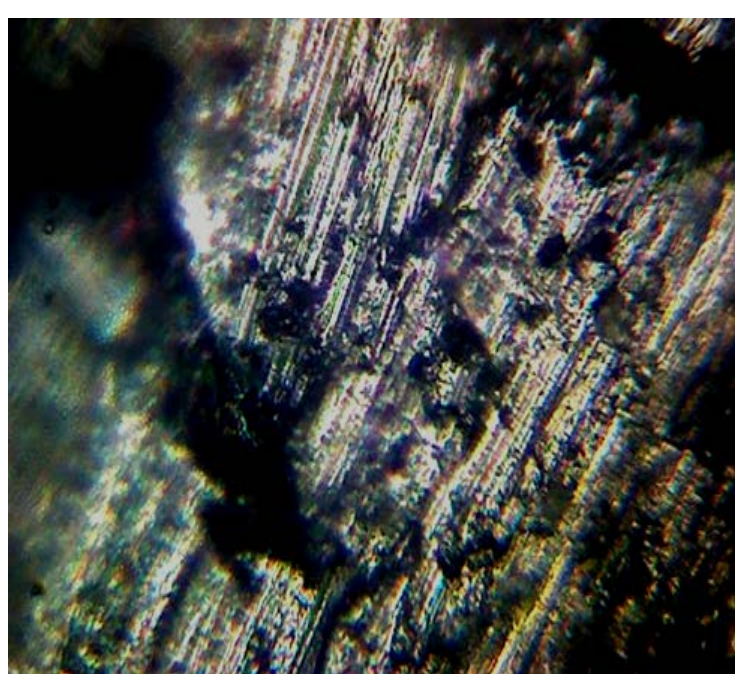

Figure $7.90 \% \mathrm{Al}-10 \% \mathrm{Ni}$.

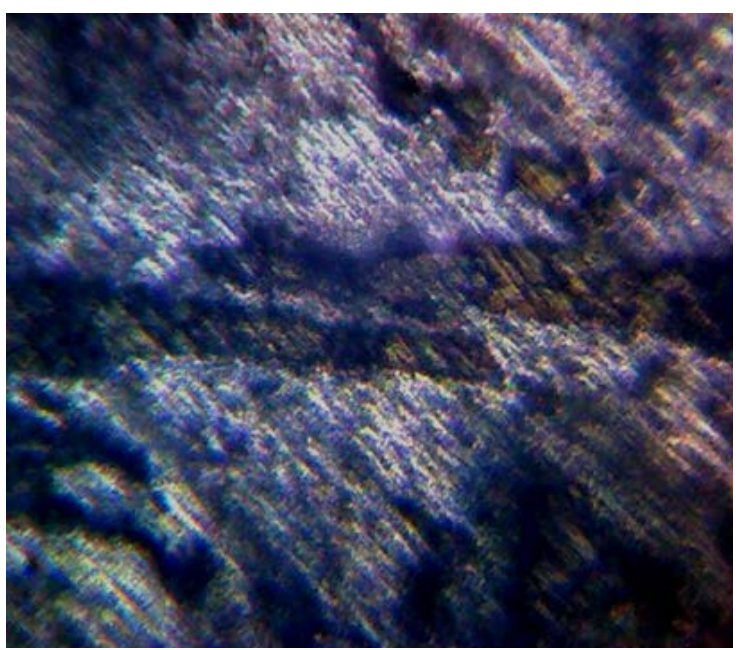

Figure $8.80 \% \mathrm{Al}-20 \% \mathrm{Ni}$.

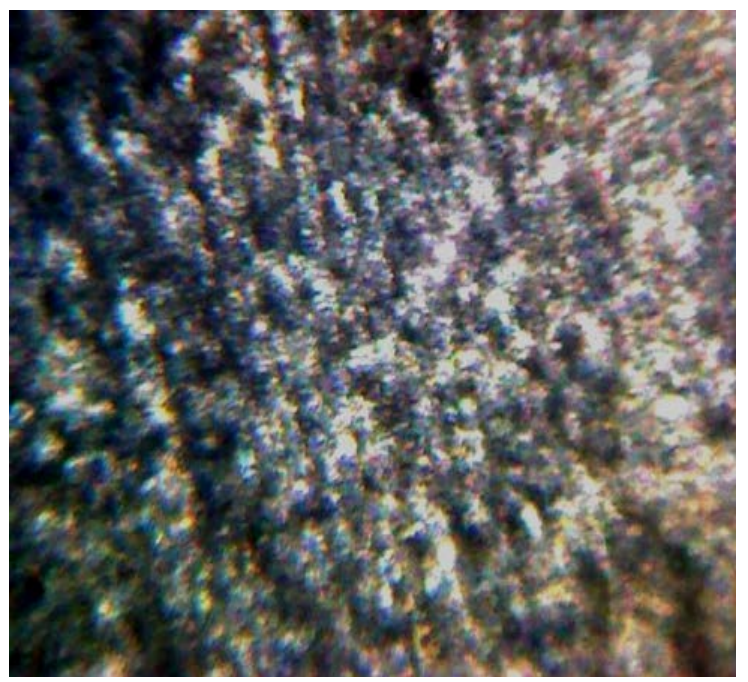

Figure 9. 70\% $\mathrm{Al}-30 \% \mathrm{Ni}$. 


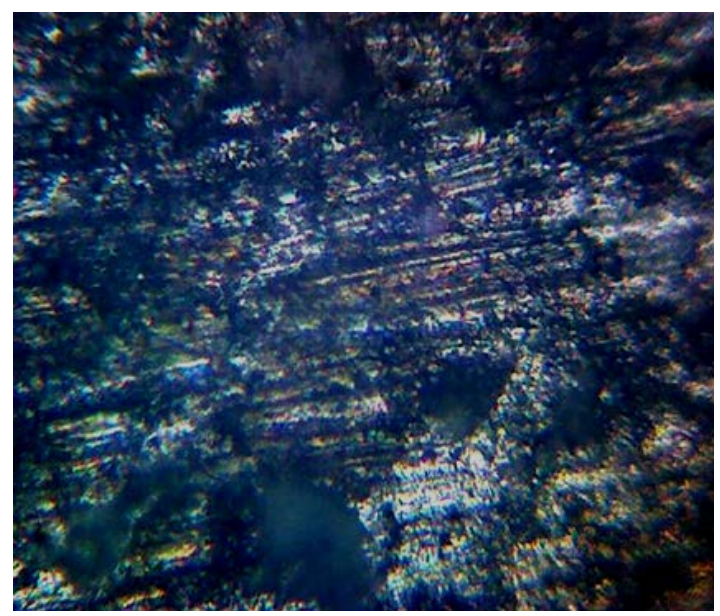

Figure 10. 60\% Al-40\% Ni.

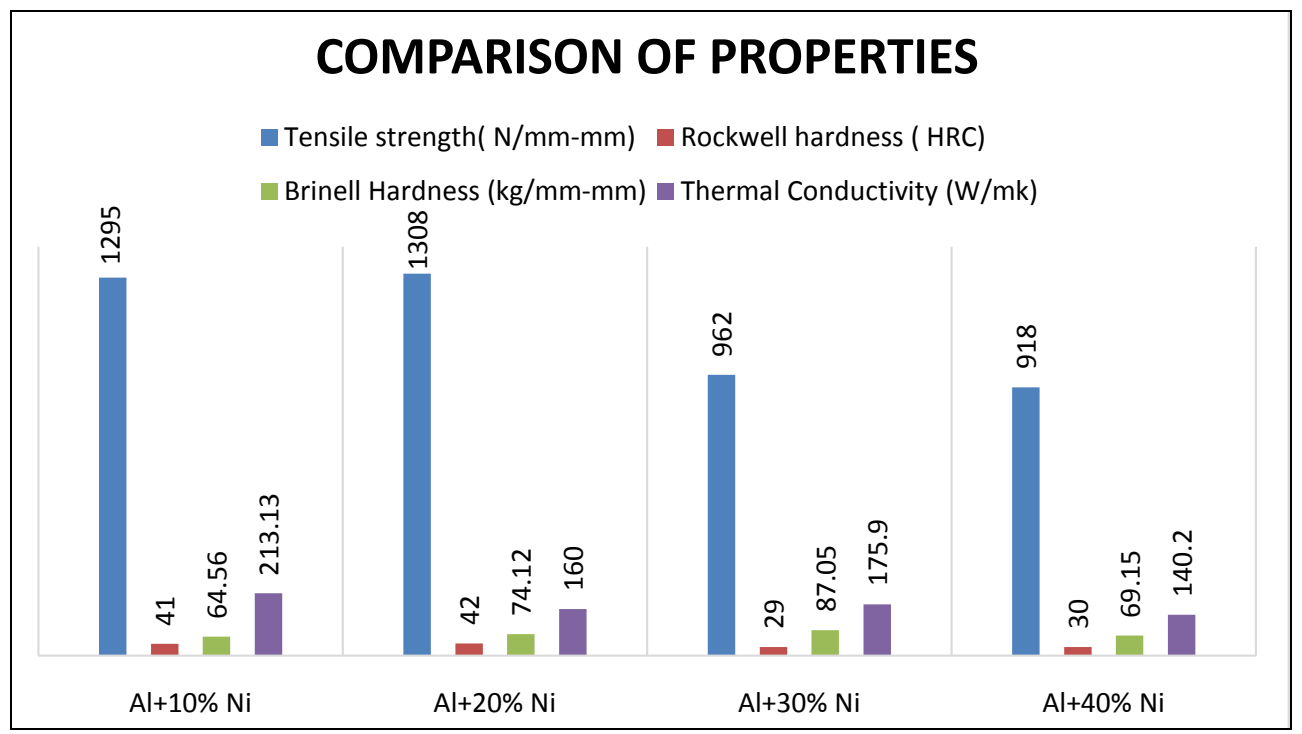

Figure 11. Graph showing the comparison of properties of the specimens in a nutshell.

Table 5. Summary of the properties of $80 \% \mathrm{Al}-20 \%$ Ni specimen.

\begin{tabular}{cc}
\hline Property & $\mathbf{A l}+\mathbf{2 0} \% \mathbf{~ N i}$ \\
\hline Tensile Strength & $1308 \mathrm{~N} / \mathrm{mm}^{2}$ \\
Rockwell Hardness & $42 \mathrm{HRC}$ \\
Brinell Hardness & $74.12 \mathrm{~kg} / \mathrm{mm}^{2}$ \\
Thermal Conductivity & $160 \mathrm{~W} / \mathrm{Mk}$ \\
\hline
\end{tabular}

The properties of this specimen were found to be better than other specimens. The Brinell hardness of $\mathrm{Al}+20 \%$ $\mathrm{Ni}$ increases by $14.80 \%$, Rockwell hardness increases by $2.43 \%$ and ultimate tensile strength increases by $1.003 \%$, whereas the thermal conductivity of $\mathrm{Al}+20 \% \mathrm{Ni}$ decreases by $24.98 \%$. So, after looking and investigating all these results we can say that the specimen $\mathrm{Al}+20 \% \mathrm{Ni}$ has applications in automotive industries as cylinder walls, engine cooling packs, cycle frames and pistons.

\section{Acknowledgements}

It gives us a great sense of pleasure to present this research work. We are grateful to all the faculties of Depart- 
ment of Mechanical Engineering, SRM University (NCR Campus) for their constant support and guidance throughout the course of our work. Their sincerity, thoroughness and perseverance have been a constant source of inspiration for us. It is through his cognizant efforts that our endeavor has seen the light of day. Last, but not the least, a special thanks to Almighty for bestowing His blessings on us always.

\section{References}

[1] Reddy, S.U. (2005) Synthesis, Mechanical and Tribological Characteristics of Mg=SiC Metal-Matrix Composites. Department of Mechanical Engineering, National University of Singapore, Singapore.

[2] Oh, S.Y., Cornie, J.A. and Russell, K.C. (1989) Wetting of Ceramic Particulates with Liquid Aluminum Alloys: Part II. Study of Wettability. Metallurgical Transactions, 20, 533-541. http://dx.doi.org/10.1007/BF02653933

[3] Telang, A.K., Rehman, A., Dixit, G. and Das, S. (2010) Alternate Materials in Automobile Brake Disc Applications with Emphasis on Al Composites: A Technical Review. Journal of Engineering Research and Studies, 1, 35-46.

[4] Singla, M., Dwivedi, D.D., Lakhvir, S. and Chawla, V. (2009) Development of Aluminium Based Silicon Carbide Particulate Metal Matrix Composite. Journal of Minerals and Materials Characterization and Engineering, 8, 455-467. http://dx.doi.org/10.4236/jmmce.2009.86040

[5] Lee, J.C. and Subramanian, K.N. (1993) Effect of Cold Rolling on the Elastic Properties of (A1203) p-Al Composite. Journal of Materials Science, 28, 1578-1584. http://dx.doi.org/10.1007/BF00363352

[6] Tan, M., Xin, Q., Li, Z. and Zong, B.Y. (2001) Influence of $\mathrm{SiC}$ and $\mathrm{Al}_{2} \mathrm{O}_{3}$ Particulate Reinforcements and Heat Treatments on Mechanical Properties and Damage Evolution of Al-2618 Metal Matrix Composites. Journal of Materials Science, 36, 2045-2053. http://dx.doi.org/10.1023/A:1017591117670

[7] Sakthive, A., Palaninathan, R., Velmurugan, R. and Rao, P.R. (2008) Production and Mechanical Properties of SiC Particle Reinforced 2618 Aluminium Alloy Composites. Journal of Materials Science, 43, 7047-7056. http://dx.doi.org/10.1007/s10853-008-3033-Z

[8] Shorowordi, K.M., Laoui, T., Haseeb, A.S.M.A., Celis, J.P. and Froyen, L. (2003) Microstructure and Interface Characteristics of $\mathrm{B}_{4} \mathrm{C}, \mathrm{SiC}$ and $\mathrm{Al}_{2} \mathrm{O}_{3}$ Reinforced $\mathrm{Al}$ Matrix Composites: A Comparative Study. Journal of Materials Processing Technology, 142, 738-743. http://dx.doi.org/10.1016/S0924-0136(03)00815-X

[9] Saleh, H.R. (2010) Mechanical Properties of the Modified Al-12\% Si Alloy Reinforced by Ceramic Particles. Eng. and Tech. Journal, 28, 289-290.

[10] Prasad, S.V. and Asthana, R. (2004) Aluminium Metal-Matrix Composites for Automotive Applications: Tribological Considerations. Tribology Letters, 17, 445-453. http://dx.doi.org/10.1023/B:TRIL.0000044492.91991.f3

[11] Dolata-Grosz, A., Dyzia, M. and Oeleziona, J. (2008) Solidification Curves and Structure of Heterophase Composite. Archives of Materials Science and Engineering, 29, 10-15.

[12] Ambhai, K.G. (2007) Study on Machinability of Al-SiC Particulate Metal Matrix Composite. Ph.D. Thesis, Metallurgical Engineering Department, IIT Roorkee, Roorkee.

[13] Clyne, T.W. (2001) 3.7.12. Metal Matrix Composites: Matrices and Processing. In: Mortensen, A., Ed., Encyclopedia of Materials: Science and Technology, Composites: $M M C, C M C, P M C$, Elsevier, New York, 1-14.

[14] Shivalingappa, D. (2007) In-Situ Magnesium Based Composites-Development and Tribological Behavior. Ph.D. Thesis, Metallurgical Engineering Department, IIT Roorkee, Roorkee.

[15] Sathyabalan, P., Selladurai, V. and Sakthivel, P. (2009) ANN Based Prediction of Effect of Reinforcements on Abrasive Wear Loss and Hardness in a Hybrid MMC. American Journal of Engineering and Applied Sciences, 2, 50-53.

[16] Aqida, S.N., Ghazali, M.I. and Hashim, J. (2004) Effects of Porosity on Mechanical Properties of Metal Matrix Composite: An Overview. Jurnal Teknologi, 40, 17-32. http://dx.doi.org/10.11113/jt.v40.395 